\title{
A study on important factors influencing innovation on computer hardware equipment: An empirical investigation using structural equation modeling
}

\author{
Naser Azad $^{a^{*}}$, Yahya Rostamniab and Javad Tazaric
}

${ }^{a}$ Department of Management, Islamic Azad University, South Tehran Branch, Tehran, Iran

${ }^{b}$ Master student in Business Administration, Payam Noor University, Iran

${ }^{c}$ Master student in Business Administration, Islamic Azad University, Rasht Branch, Rasht, Iran

\section{H R O N I C L E

$$
\text { A B S T R A C T }
$$

Article history:

Received October 27, 2012

Received in revised format

29 January 2013

Accepted 18 February 2013

Available online

February 212013

Keywords:

Hardware equipment

Structural equation modeling

Innovation

\begin{abstract}
Computer hardware business and computer equipment have been growing industry in Iran and there have been growing interests on increasing market share based on creating innovative ideas. In this paper, we present an empirical investigation to find out important factors influencing this industry. The proposed study of this paper designs a questionnaire and using 225 experts' feedbacks implements a structural equation modeling and extracts four factors including "agile management", "firms' position in business environment", "dynamic environment" and "dynamic market". The most important sub factors in detected items are strategic planning, market share, trade communications as well as rules and regulations.
\end{abstract}

(C) 2013 Growing Science Ltd. All rights reserved.

\section{Introduction}

Innovation plays an important role on increasing productivity and efficiency of organizations (Swan et al., 1999) and there are literally various studies associated with the relationship between innovation and productivity. Crespi and Zuniga (2011) studied the determinants of technological innovation and its effect on firm labor productivity across Latin American countries based on micro data from innovation investigation. They reported that investments in knowledge were more able to introduce new technological advances and those that innovate had greater labor productivity than those that did not. Donate and Guadamillas (2011) analyzed how organizational factors such as cultural values, leadership and human resource (HR) practices impact knowledge exploration and exploitation practices and innovation. They provided some evidence of a moderating influence of knowledgecentered culture, knowledge-oriented leadership and knowledge-centered HR practices in an association between knowledge exploration and exploitation practices and innovation outcomes of companies. They concluded that although knowledge management practices were important on their

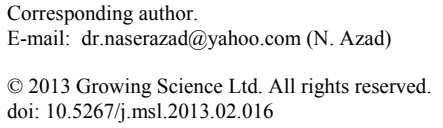


own for innovation purposes, when certain enablers - organizational factors to overcome human barriers to knowledge management were properly established, the innovation capacity of the firm could be exploited, more successfully.

According to Jiménez-Jiménez and Sanz-Valle (2011) there are various investigations on the relationship between innovation and performance and the results have asserted a positive relationship between organizational learning and both performance and innovation. They reported that organizational learning and innovation could contribute positively to business performance, and organizational learning influences innovation.

Kammerer (2009) performed an empirical investigation among some German appliance manufacturing firms by investigating the impacts of customer benefit and regulation on environmental product innovation. The results of this survey supported the issue level as unit of analysis. Kostopoulos et al. (2011) investigated the impact of absorptive capacity as a mechanism to detect external knowledge inflows into tangible benefits, as well as a method of achieving superior innovation and time-lagged financial performance.

Laforet (2008) investigated how size, strategic, and market orientation could influence on innovation while Makri and Scandura (2010) explored the effects of creative CEO leadership on innovation in high-technology firms. McFadzean et al. (2005) examined the literature on corporate entrepreneurship and innovation and developed a comprehensive definition for them. They also build a holistic model, which explained the links between corporate entrepreneurial activity and the innovation process.

Moreno et al. (2011) explained that a context characterized by cohesion, recognition, some degree of formalization, and decentralization could possibly create a work climate, which fosters innovation, enabling service businesses to adapt better to their environment. Orlandi (2010) identified the relationship between creativity, innovation and design associated with design education by exploring the educational structures through history of design and design education that leads to creative thinking and nurture sustainable innovation.

Şener and Sarıdoğan (2011) investigated the impacts of science-technology-innovation on competitiveness and economic growth and reported that countries, which had science-technologyinnovation oriented global competitiveness strategies could build a sustainable competitiveness and long run growth. Soltani et al. (2010) studied the role of training in facilitating innovation in small food industries in rural areas of Iran. Lee et al. (2010) investigated the effect of relationship style on innovation performance. Finally, Wu (2011) studied asymmetric roles of business ties and political ties in product innovation and finally Valencia et al. (2010) studied organizational culture as determinant of product innovation.

In this paper, we present an empirical investigation to find out important factors influencing this industry. The organization of this paper first presents details of the study in section 2 and section 3 presents the results of our survey. Finally, concluding remarks are given in the last to summarize the contribution of the paper.

\section{The proposed study}

The proposed study of this paper uses 225 experts to find important factors on having more innovative ideas on hardware equipment using a structural equation modeling studies. In our survey, $36.7 \%$ of the participants were male, $55.8 \%$ were female and $7.4 \%$ of the participants did not specify their gender. In terms of educational background, $9.3 \%$ of the surveyed only finished high school, 20.5\% had 2-year college degree, 44.7 maintained bachelor degree, 13\% hold master's degree, 1.9\% hold $\mathrm{PhD}$ degree and $10.7 \%$ did not specify any thing about their degree. Cronbach alpha was calculated as $88 \%$, which validates the questionnaire of this survey. In addition, the questionnaire consists of 32 questions but only variables with strong statistics in terms of variance are reported. 


\section{The results}

In this section, we present details of our findings in terms of factor analysis and the results of our survey indicate that there are four important factors.

\subsection{Agile management}

The first component of our survey is associated with agile management. Cronbach alpha has been calculated as 0.86 and the percentage of variance is equal to 0.64 and Kaise Mayor index is equal to 0.86 , which means the sample is sufficient. There are 12 important factors with different $\%$ of variances including organizational learning (0.38), employee information (0.62), existence of information technology (0.77), existence research and development (0.73), strategic planning (0.71), product development (0.54), organizational culture (0.66), leadership style (0.72), employee learning capabilities (0.59), organization conditions $(0.47)$, creating new ideas $(0.53)$ and top management (0.36). As we can observe, existence of information technology is the most important sub-factor followed by employee capabilities on learning new ideas and strategic planning.

\subsection{Organizational position in business environment}

The second factor is our survey is associated with organization position in business environment and Cronbach alpha has been calculated as 0.77 . In our survey, this factor describes $34 \%$ of variance of changes and related statistics indicate that the sample has been sufficient. This factor contains six factors including firm size (0.42), firm history (0.69), financial performance (0.44), market share (0.71), cost of raw materials (0.53), existing potentials $(0.53)$ and competitors $(0.48$. While market share and firm history are the most important factors, firm size and financial performance did not seem to be important factors.

\subsection{Dynamic environment}

Dynamic environment is the third component of our factor analysis, Cronbach alpha is equal to 0.70 and Kaiser-Mayor $=0.86$. There are seven factors associated with this factor including total quality management (0.54), market design (0.58), political affairs (0.60), trade communications (0.76), technology change (0.49), market diversity (0.49) and distribution channels (0.45). The results indicate that trade communications is the most important sub-component followed by political affairs and total quality management.

\subsection{Dynamic of product}

Finally, dynamic of product is the last factor in our survey with percentage of variance is equal to 0.48 and Kaiser-Mayor ratio is equal to 0.86 . The factor includes four sub-component including customer attitude (0.41), customer benefit (0.46), rules and regulations (0.76) and market elasticity (0.60). The results indicate that rules and regulations is the most important factor followed by market elasticity.

We have also implemented structural equation modeling to study the relationships between different components, Fig. 1 demonstrates the results of our investigations and Table 1 shows the results of statistical observation for testing SEM model. 
Table 1

The results of implementation of structural equation modeling

\begin{tabular}{cccccccccc}
\hline CMIN & df & CMIN/df & RMSEA & GFI & AGFI & IFI & CFI & RMR \\
\hline 230.82 & 120 & 1.92 & 0.06 & 0.91 & 0.84 & 0.93 & 0.93 & 0.07 \\
\hline
\end{tabular}

The results of Table 1 indicate that all statistical observations are within acceptable limits and we can validate the results of our SEM implementation. For instance, both GFI and AGFI are well above 0.90 , which is the minimum acceptable value.

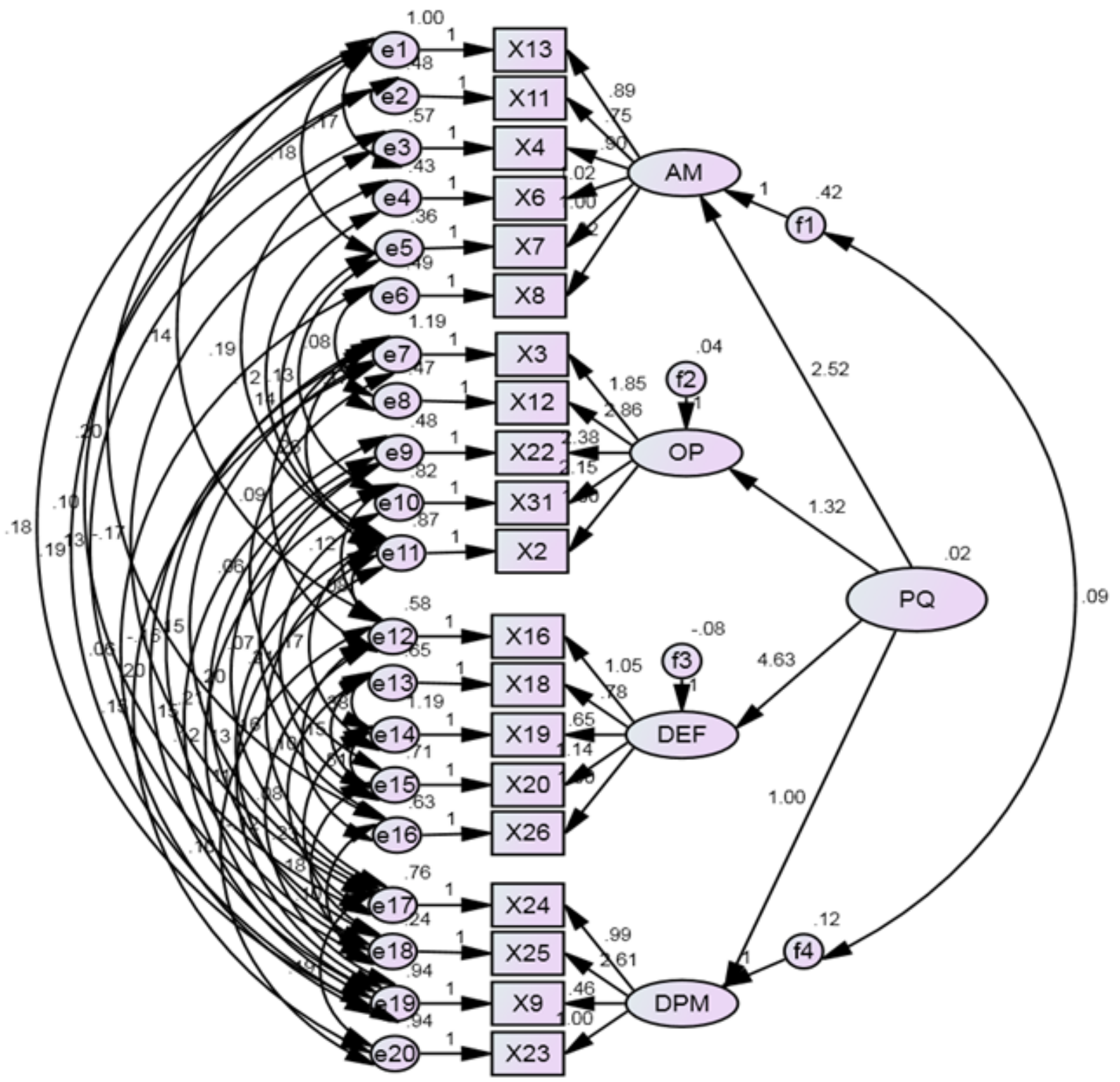

Fig. 1. The results of structural equation modeling

In terms of different components of our survey, we have measured various detailed statistics and Table 2 demonstrates the results of our survey. 
Table 2

The results of statistical observations for SEM

\begin{tabular}{|c|c|c|c|c|c|c|c|}
\hline Component & RMR & CFI & IFI & AGFI & GFI & RMSEA & CMIN/df \\
\hline Agile management & 0.03 & 0.97 & 0.97 & 0.93 & 0.96 & 0.08 & 2.51 \\
\hline Company position & 0.05 & 0.94 & 0.94 & 0.91 & 0.97 & 0.09 & 3.09 \\
\hline Dynamic environment & 0.02 & 0.99 & 0.99 & 0.94 & 0.98 & 0.06 & 1.99 \\
\hline Dynamic product development & 0.006 & 1.00 & 1.00 & 0.99 & 1.00 & 0.00 & 1.00 \\
\hline
\end{tabular}

The results of Table 2 also indicate that all statistical observations are within acceptable limits and we can validate the model in terms of detailed components. In Fig. 1, all questions are demonstrated with Q1 to Q31, AM represent agile management, OP stands for organizational position in business environment, DEF shows dynamic environment and finally DPM demonstrates dynamic of product development. The effects of each component on other factors along with t-student values are also demonstrated in Fig. 1. The results of SEM are consistent with the results obtained through the implementation of Pearson correlation ratios.

\section{Conclusion}

In this paper, we have presented an empirical study to investigate important factors influencing innovative ideas in computer hardware industry. The proposed study of this paper has detected four influencing factors including agile management, organizational position in business environment, dynamic environment and product. The most important sub factors in detected items are strategic planning, market share, trade communications as well as rules and regulations.

\section{Acknowledgment}

The authors would like to thank the anonymous referees for constructive comments on earlier version of this paper.

\section{References}

Crespi, G., \& Zuniga, P. (2011). Innovation and productivity: evidence from six Latin American countries. World Development, 40(2), 273-290.

Donate, M. J., \& Guadamillas, F. (2011). Organizational factors to support knowledge management and innovation. Journal of Knowledge Management,15(6), 890-914.

Jiménez-Jiménez, D., \& Sanz-Valle, R. (2011). Innovation, organizational learning, and performance. Journal of Business Research, 64(4), 408-417.

Kammerer, D. (2009). The effects of customer benefit and regulation on environmental product innovation.: Empirical evidence from appliance manufacturers in Germany. Ecological Economics, 68(8), 2285-2295.

Kostopoulos, K., Papalexandris, A., Papachroni, M., \& Ioannou, G. (2011). Absorptive capacity, innovation, and financial performance. Journal of Business Research, 64(12), 1335-1343.

Laforet, S. (2008). Size, strategic, and market orientation affects on innovation. Journal of Business Research, 61(7), 753-764.

Lee, H. W., \& Yu, C. F. (2010). Effect of relationship style on innovation performance. African Journal of Business Management, 4(9), 1703-1708.

Makri, M., \& Scandura, T. A. (2010). Exploring the effects of creative CEO leadership on innovation in high-technology firms. The Leadership Quarterly,21(1), 75-88.

McFadzean, E., O'Loughlin, A., \& Shaw, E. (2005). Corporate entrepreneurship and innovation part 1: the missing link. European Journal of Innovation Management, 8(3), 350-372. 
Moreno, A. R., Domínguez, M. C. H., \& Egea, T. O. (2011). The influence of quality management on orientation to innovation in service firms. African Journal of Business Management, 5(17), 8997 9006.

Orlandi, A. E. C. (2010). Experimental experience in design education as a resource for innovative thinking: The case of Bruno Munari. Procedia-Social and Behavioral Sciences, 2(2), 5039-5044.

Swan, J., Newell, S., Scarbrough, H., \& Hislop, D. (1999). Knowledge management and innovation: networks and networking. Journal of Knowledge management, 3(4), 262-275.

Şener, S., \& Sarıdoğan, E. (2011). The effects of science-technology-innovation on competitiveness and economic growth. Procedia-Social and Behavioral Sciences, 24, 815-828.

Soltani, S., Hosseini, S. J., \& Mirdamadi, S. M. (2010). The role of training in facilitating innovation in small food industries in rural Iran. African Journal of Agricultural Research, 5(17), 2332-2340.

Valencia, J. C. N., Valle, R. S., \& Jiménez, D. J. (2010). Organizational culture as determinant of product innovation. European Journal of Innovation Management, 13(4), 466-480.

$\mathrm{Wu}$, J. (2011). Asymmetric roles of business ties and political ties in product innovation. Journal of Business Research, 64(11), 1151-1156. 